\title{
EDITORIAL \\ DR. EDMUND ALEXANDER PARKES, M.D., F.R.S. \\ 1819 to 1876
}

THIS number of the journal commemorates the centenary of the death of Dr. Parkes, first Professor of Hygiene at the Army Medical School. By way of tributes to his memory we publish the proceedings of the commemoration ceremony held at the Royal Army Medical College on 5 May 1976. These comprise Dr. Wilfrid Harding's memorial lecture, the Director General's introduction and a brief biographical appreciation by Colonel Crowdy. In addition a specially commissioned article is contributed by Dr. George Rosen, professor of the History of Science and Medicine at Yale University. Any reader who wonders what reasons justified a centenary commemoration will quickly have his doubts dispelled by reading the collected papers in this issue. Between them the articles highlight the remarkable characteristics of a remarkable man. Professor Rosen, in his selective but well chosen analysis of Parkes' work and writings draws attention to his great reputation as a teacher and innovator. Parkes was also an experimental worker in the field of epidemiology and physiology, two subjects which he saw as axiomatic to the emerging science of hygiene.

But the purpose of a centenary is not fulfilled by reflection on past accomplishments or even by the necessary refurbishing of the memory of great achievements which have become dulled with the passage of time. A further compelling purpose motivating this centenary was the need to reactivate Parkes' work and wisdom, to use these features as a torch to light the way forwards for the future of military hygiene, and to reassert the Army's role as leaders in preventive medicine.

While it is satisfying to look back with a justified pleasure on the past, too much retrospective gazing dulls the mind into an unwarranted complacency. The roseate glow from the halycon era of Parkes' eminence, his sixteen years as Professor of Hygiene at the Army Medical School, cannot fuel the furnaces of further progress unless there is added by today's protagonists an element of present enterprise and determination to reactivate the great historical reputation.

To the nineteenth century world of medicine and militarism alike Parkes demonstrated the outstanding importance of hygiene as means of enhancing the public health and, more particularly, as the way to improve the health of the soldier in war and peace. To Parkes may be ascribed the accolade, following in the Nightingale tradition, for being the first systematic teacher of preventive medicine. So effective were his writings that the fundamental lesson that medical officers should be concerned primarily with prevention remains enshrined in regulations as the first function of the Army Medical Services, namely. "The prevention of disease and the promotion of health". To Parkes may be attributed also the promotion of hygiene (now Army Health, perhaps tomorrow Community Health) to be a major discipline with specialist status within the Army Medical Services. Whereas Parkes initiated this concept, and indeed launched the specialist sanitary officer (as he was called in those early days), it remained to his successors, and particularly to Sir William Horrocks the first Director of Hygiene, to preserve the rightful status of the discipline in the Army when in civil life there was a sad and unfortunate decline, only recently reversed by the emergence of Community Medicine in the National Health Service reorganization. 
But the message of the centenary commemoration, pointed so distinctly and so cogently by Dr. Harding in his memorial lecture, is that Hygiene, Army Health, Community Medicine--call it what you will-cannot remain dormant. Methods have changed since Parkes' day but what has not changed is the need for an enquiring approach, for a research-based programme of advance towards the newer frontiers of military preventive medicine. Parkes did just this before his untimely death at the height of his career. The principal purpose of his centenary commemoration is to ensure that the same sage counsels prevail in the contemporary scene.

\section{INTRODUCTION BY DGAMS TO PARKES MEMORIAL CENTENARY LECTURE}

WE are tonight commemorating the life and work of Dr. Edmund Alexander Parkes who died a century ago. He was the first Professor of Hygiene, appointed to the newly created Army Medical School at Fort Pitt, Chatham in 1860. His work during the 16 years of his tenure as Professor, was done at a time of rapid change in both military and civilian public health, and Dr. Parkes was able to exercise his influence on this evolution, through his experimental work, his writing of papers and reports, and his ability to combine theory and practice. This was the era of the great sanitarians and among them Parkes was pre-eminent, possibly the greatest of the century.

Dr. Parkes received many honours during his lifetime, and after his death at the early age of 57 years, there was an overwhelming public response to commemorate his name. The Parkes Museum of the Royal Society of Health, to which Queen Victoria herself gave $£ 50$, has been dispersed. Within the Services his name lives on in the Parkes Memorial Prize, awarded annually to the officer who has done most by professional work of outstanding merit to promote the study of naval or military hygiene. But his place as a pioneer of public health and military hygiene has tended to be forgotten. It is our purpose to revive his memory and to pay tribute to a man who could be said to have done more than any other to improve and safeguard the soldier's health.

It is perhaps appropriate that this centenary falls at a time when further changes are taking place in what was the discipline of hygiene but is now part of community medicine. The changes in Parkes's time were fundamental and basically scientific in origin; today they are mainly organisational in nature, although the aim of a better health service remains true. We are very fortunate tonight, to have with us Dr. Wilfrid Harding President of the Faculty of Community Medicine, as our centenary lecturer. His lecture is entitled "Service, Community and Health"-a combination which I am sure would commend itself to Dr. Parkes.

Dr. Harding is the Area Medical Officer of Camden and Islington Area Health Authority, and is responsible for the health care of the half-million population in this concentrated urban area. Like Dr. Parkes, Dr. Harding is a graduate of University College Hospital, where he qualified in 1941. He spent the war years, 1943 to 1946 in the R.A.M.C., being wounded during the campaign in Europe when serving with 53 Welsh Division. Later he returned to Germany, where his fluent knowledge of the 